\title{
Proving Genocide? Forensic Expertise and the ICTY
}

\author{
Melanie Klinkner*
}

\begin{abstract}
This article works towards developing a theoretical framework outlining the premises and parameters under which forensic experts operate during various stages of international criminal investigations and the presentation of expert witness testimony in court. With reference to law and science literature, the article explores the reasons for undertaking resource-intensive forensic investigations; secondly it outlines the ways in which evidence is gathered and interpreted, the process of constructing 'forensic truth'; and finally it examines what happens to 'forensic truth' once it enters the legal arena. The International Criminal Tribunal for the former Yugoslavia (ICTY) and its activities are used to illustrate the issues involved during the forensic expertise meets international law' interface. Specifically the forensic exhumations conducted around the Srebrenica events of July 1995 and their use in the Krstic trial serve to contextualise the debate.
\end{abstract}

\section{Introduction}

Between 10 and 19 July the so called United Nations (UN) 'safe area' of Srebrenica was captured by units of the Bosnian Serb Army. Many thousands of military-aged men were captured and killed as they tried to flee, whilst women, children and elderly people were uprooted and transported under terrifying conditions to Bosnian Muslim-held territory. During the Krstic trial forensic evidence from mass graves corroborated the testimonies of witnesses concerning the mass executions and burial of thousands of Bosnian Muslim men. The forensic evidence, which included reports on the exhumations, autopsies and laboratory analysis as well as photographic evidence, material artefacts and expert witness testimony, helped to establish the actus reus of the crimes and contributed to ascertaining the 'intent to destroy, in whole or in part, a national, ethnical, racial or

* MA, Albert-Ludwigs Universität Freiburg, Ph.D. candidate, Bournemouth University. The author wishes to thank Prof. Nick Grief and Prof. Margaret Cox for their continuous guidance and advice as well as Bournemouth University and The Harold Hyam Wingate Foundation for financially supporting this research. [mklinkner@bournemouth.ac.uk] 
religious group, as such ${ }^{1}$ (the mental element of genocide according to the Genocide Convention). In order to generate this type of information, the forensic expertise needed comprised various disciplines such as forensic anthropology, archaeology and pathology.

Many scientists have shared their ICTY experiences of mass grave exhumations, post-mortem examinations and analysis $;^{2}$ and legal experts have commented on rules of evidence and international criminal proceedings. ${ }^{3}$ Whilst the topic of scientific evidence in court has been explored in various national settings, ${ }^{4}$ this has yet to be related to an international legal framework. Similarly, an assessment of the complex relations between forensic experts involved during atrocity crime investigations, their conclusions, and the lawyers who interpret these at an international tribunal is still to come. This paper explores how the forensic experts' gathering of facts and scientific interpretation of events, the construction of 'forensic truth', finds its way into trials where it is reinterpreted by legal experts to achieve "procedural truth" ${ }^{5}$ expressed through the verdict. This exploration within the context of international justice is all the more important as

\footnotetext{
${ }^{1}$ Article 4(2) ICTYSt and Article 2, UN Convention on the Prevention and Punishment of the Crime of Genocide (1948).

2 E.g. W.D. Haglund, 'Recent Mass Graves: An Introduction', in W.D. Haglund and M.H. Sorg (eds), Advances in Forensic Taphonomy: Method, Theory and Archaeological Perspectives (Boca Raton, London: CRC Press, 2002) 243-261 and S. Schmitt, 'Mass Graves and the Collection of Forensic Evidence: Genocide, War Crimes, and Crimes against Humanity', in W.D. Haglund and M.H. Sorg (eds), Advances in Forensic Taphonomy: Method, Theory and Archaeological Perspectives (Boca Raton, London: CRC Press, 2002) 277-292.

${ }^{3}$ E.g. K.D. Rutledge, "'Spoiling Everything" - but for Whom? Rules of Evidence and International Criminal Proceedings', 16 Regent University Law Review (2003) 151-189; R. May and M. Wierda, 'Trends in International Criminal Evidence: Nuremberg, Tokyo, The Hague, and Arusha', 37 Columbia Journal of Transnational Law (1999) 752-766.

${ }^{4}$ Neil Browne and his colleagues concentrate on expert testimony in the US, England, Korea and France (N.M. Browne, C.L. Williamson, and L.L. Barkacs, 'The Perspectival Nature of Expert Testimony in the United States, England, Korea and France', 18 Connecticut Journal of International Law (2002) 55-102), whilst Sheila Jasanoff and Gary Edmond examine the use of science in US and Australian courts respectively (S. Jasanoff, 'Just Evidence: The Limits of Science in the Legal Process', 34 Journal of Law, Medicine \& Ethics (2006) 328-341; G. Edmond, 'Science, Law and Narrative', 23 Southern Illinois University Law Journal (1999) 555-583).

${ }^{5}$ The term 'procedural truth' is taken from T. Weigend, 'Is the Criminal Process About Truth? A German Perspective', 29 Harvard Journal of Law \& Public Policy (2003) 157-173.
} 
some transitional justice scholars believe that one rationale for, and a function of, justice is to create an accurate historical record. ${ }^{6}$

For illustration, this article concentrates on the Srebrenica investigations ${ }^{7}$ and the presentation of forensic evidence during the Krstic case. Using trial transcripts and reviewing literature from across the disciplines generates an account of why forensic experts are invited to engage in international investigations, what their role during the investigations is and how their findings enter the legal arena. Through analysis of the relevant material, the potential and limitations of forensic evidence, which is by definition embedded within a legal context, and its use, will become evident.

\section{Why Seek Forensic Expertise?}

As Deputy Commander of the Bosnian Serb Army (VRS), Radislav Krstić was charged with genocide, crimes against humanity and violations of the laws or customs of war. ${ }^{8}$ To establish that killings on a mass scale which may qualify as genocide had actually occurred, the prosecution had to collect relevant evidence to prove the dolus specialis behind the deed, showing that the crimes were planned with the specific intention of destroying a particular national, ethnical, racial or religious group, as such. Forensic experts could help gather and interpret admissible evidence to provide 'unequivocal

\footnotetext{
${ }^{6}$ Michael Scharf and Paul Williams, for example, believe that the creation of a historical record is one element of the justice process needed to create peaceful societies after war: 'These include establishing individual responsibility and denying collective guilt, dismantling and discrediting institutions and leaders responsible for the commission of atrocities, establishing an accurate historical record, providing victim catharsis, and promoting deterrence' (M. Scharf and P. Williams, 'The Functions of Justice and AntiJustice in the Peace-Building Process', 35 Case Western Reserve Journal of International Law (2003) 161190 , at 170$)$.

${ }^{7}$ The investigations into the Srebrenica massacres from 1996 onwards are documented in Dean Manning's summary report (D. Manning (ICTY Investigator), 'Srebrenica Investigations. Summary of Forensic Evidence - Execution Points and Mass Graves', ICTY, 16 May 2000, available at: http://www.domovina.net/archive/2000/20000516_manning.pdf (visited 25 January 2007)).

${ }^{8}$ Amended Indictment, Krstić (IT-98-33), 27 October 1999, §§ 21-33.
} 
corroboration to what could otherwise be suspect or dubious evidence. ${ }^{9}$ Consequently, forensic experts were invited to undertake forensic investigations and exhumations under the ICTY started on 7 July in 1996 at Cerska, near Srebrenica. ${ }^{10}$ The role of forensic experts included:

- Examining and interpreting material to provide relevant, previously unknown information;

- Collating results into a report for the prosecution, potentially for the defence and for presentation in court;

- Presenting verbal evidence as expert witnesses during a trial. ${ }^{11}$

As Krstić was accused, inter alia, of genocide, the information needed by the prosecution for his trial was the 'categorical identification' of dead bodies: i.e. establishing the ethnicity, religion, ancestry, cause and manner of death, as well as attempting to establish the link between Krstić and the crimes to show his personal intent.

\section{3. 'How you come out in a case often depends on how you go in'12 - Construction of 'Forensic Truth'}

The contexts in which lawyers and forensic experts interact during criminal investigations can be divided into three main areas: pre-forensic investigation, forensic

\footnotetext{
${ }^{9}$ G.T. Blewitt, 'The Role of Forensic Investigations in Genocide Prosecutions before an International Criminal Tribunal', 37 Medicine, Science and the Law (1997) 284-288, at 284.

${ }^{10}$ Third Annual Report of the International Tribunal for the Prosecution of Persons Responsible for serious Violations of International Humanitarian Law committed in the Territory of the Former Yugoslavia since 1991. UN doc. A/51/292-S/1996/665, 16 August 1996, § 79.

${ }^{11}$ See P. Cobb, 'Forensic Science', in P. White (ed), Crime Scene to Court. The Essentials of Forensic Science (Cambridge: The Royal Society of Chemistry, 1998) 1-14, at 9.

${ }^{12}$ R.J. Aldisert, 'Logic in Forensic Science', in C.H. Wechts and J.T. Rago (eds), Forensic Science and Law: Investigative Applications in Criminal, Civil, and Family Justice (Boca Raton: Taylor \& Francis, 2006) 11-34, at 28.
} 
investigation and the expert witness testimony during the trial. In each of these situations, the roles, process and assumptions influencing the collection, interpretation and presentation of forensic evidence will be discussed.

\section{A. Pre-investigation}

Once the decision to seek forensic expertise has been taken, the investigation team must establish where to find crime scenes and graves, before planning the excavation and exhumation processes. This is not necessarily a straightforward undertaking:

Merely locating a crime scene can be a formidable task. The majority of the crimes committed during the break-up of the former Yugoslavia were totally unreported. A few did attain almost instant world-wide publicity. In general, however, unspeakable atrocities took place in isolated locations, under cover of darkness, in non-descript buildings, in common fields and forests, out of sight of media cameras or military surveillance, totally unknown to the wider world. ${ }^{13}$

In August 1995, US Ambassador Madeleine Albright informed the UN Security Council of the existence of classified aerial photographs regarding Srebrenica. ${ }^{14}$ Subsequently the ICTY prosecution team, with help from a forensic expert, was able to examine the aerial images dating from 7 July and 27 July 1995. Along with eye witness testimony of survivors, disturbed soil and anomalies in geological features on the photographs led the investigation team to suspect the existence of mass graves at various sites (e.g. Cerska, Nova Kasaba). ${ }^{15}$ Through a forensic site assessment the graves were then located, confirmed and defined to facilitate meticulous planning of the exhumations.

\footnotetext{
${ }^{13}$ M.B. Harmon and F. Gaynor, 'Prosecuting Massive Crimes with Primitive Tools: Three Difficulties Encountered by Prosecutors in International Criminal Proceedings', 2 Journal of International Criminal Justice (2004) 403-409, at 405.

${ }^{14}$ See Manning, supra note 7, at 12.

${ }^{15}$ Ibid., at 9-12.
} 
Furthermore, forensic experts assisted in establishing the scope of the forensic enquiry by giving an indication as to which site would yield what type evidence.

\section{B. Forensic Investigation}

Operating under Chapter VII of the UN Charter, the OTP's forensic teams comprised forensic experts, investigators and support personnel and included dozens of people. The key positions were those of the investigator, the chief archaeologist, the chief anthropologist and the chief pathologist; the last three headed the forensic teams at the grave site or mortuary and led the forensic examination.

ICTY investigator Dean Manning summarised an investigator's duties regarding exhumations and autopsies as including:

... attendance at exhumation sites, on site briefings relating to the crime scenes, the examination and assessment of evidence in situ and the comparison of evidence obtained from various exhumation sites and autopsies, the hand over of bodies to authorities of Bosnia and Herzegovina, and the examination, assessment and transport to the ICTY offices in The Hague of evidence obtained during the exhumation and autopsy process. ${ }^{16}$

Forensic archaeologists apply their survey and excavation skills to the site; they are experienced in identifying, excavating and recording complex features, and recovering human remains and artefacts. They are also experts in recognising taphonomic alteration to soils, human remains and other materials recovered which helps elucidate what happened to the victims at the point of death and thereafter. ${ }^{17}$ During the Srebrenica

\footnotetext{
${ }^{16}$ Witness Statement by Investigations Team Leader Dean Paul Manning, Milošević (IT-02-54-T), 24 November 2003, § 4, available at: http://www.domovina.net/archive/2003/20031124_manning.pdf (visited 25 January 2007) (hereinafter Milošević Witness Statement by Investigations Team Leader Dean Paul Manning).

${ }^{17}$ M. Skinner and J. Sterenberg, 'Turf Wars: Authority and Responsibility for the Investigation of Mass Graves’, 151 Forensic Science International (2005) 221-232, at 224.
} 
investigations, primary as well as secondary graves were located: a sign of the archaeologists' ability to link execution with inhumation sites, and primary inhumation sites with secondary ones.

The forensic pathologists' main role is to perform the post-mortem examination of bodies and human remains to establish the cause of death and identity of the victims. Criminal aspects of death tend to leave physical traces and the pathologist has experience in recognising torture and/or starvation prior to death, trauma, entrance and exit wounds from firearms etc. ${ }^{18} \mathrm{He}$ or she works closely with the anthropologists, odontologists and radiographers.

Forensic anthropologists are specialists in analysing skeletal and dental remains as well as taphonomic alterations. Critically, they are able to distinguish between bones' state during an individual's lifetime, at the time of death and after death and can thus contribute towards establishing ancestry, sex, age at death, stature, handedness etc. They reconstruct fragmented and disarticulated skeletons to facilitate the calculation of the minimum number of individuals (MNI) and to aid the identification process. ${ }^{19}$

Everything that is undertaken at the site or within the mortuary is thoroughly recorded in the most appropriate media such as log books, autopsy reports, photographs, X-rays and field notes.

\footnotetext{
${ }^{18} \mathrm{Ibid}$.

${ }^{19} \mathrm{Ibid}$.
} 


\section{Limits at the Site}

Between 1996 and the end of 1999, 17 mass graves had been exhumed relating to the Srebrenica massacres, and a further 23 sites examined. ${ }^{20}$ The sites were selected according to the prosecution's strategy and the boundaries of the sites, in which the forensic experts were to work, established. As Skinner and Sterenberg observe, however, a crime has no natural boundaries. ${ }^{21}$ Through the limits set in space and in time, the scene is not the same as in the past and the representation of the actual burial scene (not to mention the crime scene) is partial. $^{22}$ Although the forensic experts' working environment has been determined, it is defined not only by the presence of data and information but also through the absence of potential evidence ${ }^{23}$ and shows the limits of scientific and objective information obtainable from such a site before the collection even starts.

\section{Operational and Institutional Constraints}

The security levels at the site and during personnel transportation are critical to facilitate successful investigations. ${ }^{24}$ Support structures such as equipment, facilities and health and safety considerations - not always a given in war-torn countries - impact on procedures and results. Inadequate equipment will compromise the quantity and quality

\footnotetext{
${ }^{20}$ Manning, supra note 7, at 4.

${ }^{21}$ Skinner and Sterenberg, supra note 17, at 227.

${ }^{22}$ For a more comprehensive description of scenes connected to crimes and the task of defining these, see Skinner and Sterenberg, ibid.

${ }^{23}$ Lorin de la Grandmaison and his colleagues in their study into ethical considerations of forensic pathologists note that some pathologists were well aware that various mass-graves were not investigated, fueling speculations of bias and misrepresentation of facts (G. Lorin de la Grandmaison, M. Durigon, G. Moutel and C. Herve 'The International Criminal Tribunal for the Former Yugoslavia (ICTY) and the Forensic Pathologist: Ethical Considerations', 48 Medicine, Science and the Law (2006) 208-212).

${ }^{24}$ Forensic scientists Skinner, Alempijevic and Djuric-Srejic account that in their experience ' $[\mathrm{t}]$ he most dangerous activity, by far, is driving to and from the site' (M. Skinner, D. Alempijevic, and M. DjuricSrejic, 'Guidelines for International Forensic Bio-Archaeology Monitors of Mass Grave Exhumations', 134 Forensic Science International (2003) 81-92, at 85).
} 
of the evidence collected and these limitations must be spelt out in court. ${ }^{25}$ Appropriate Personal Protection Equipment (PPE) can also shelter forensic scientists from smells, sights, emotions and provide confidence in the overall value and integrity of the work conducted. $^{26}$ In addition, the presence of other professional personnel is vital for the success of a mission, its coordination, documentation, administration and maintaining the chain of custody.

Forensic work is automatically embedded into time and budget constraints. Given the principle 'justice delayed is justice denied,' time is critical for the prosecution team. ${ }^{27}$ According to Browne et al., this explicitly value-driven legal approach 'contrasts sharply with the purported intellectual openness of the scientific process and its quest for more reflective understandings, under few to no time constraints. ${ }^{, 28}$ Consequently, forensic scientists, despite striving for independence and neutrality, need to complete exhumations and autopsies within a limited time-frame. ${ }^{29}$

The objectives of an exhumation are clear from the outset; for the Srebrenica investigations, as stated by investigator Dean Manning, the basic objectives were:

- to corroborate victim and witness accounts of the massacres;

- to determine an accurate count of victims;

- to determine cause of death and time of death;

- to determine the identity of the victims and any link to the missing from Srebrenica;

\footnotetext{
${ }^{25}$ J. Clark, 'Pathological Investigation', in J. Payne-James (ed.), Encyclopaedia of Forensic and Legal Medicine (London: Elsevier, 2005) 363-371, at 367.

${ }^{26}$ E.D. Williams and J.D. Crews, 'From Dust to Dust: Ethical and Practical Issues Involved in the Location, Exhumation, and Identification of Bodies from Mass Graves', 44, no.3 Croatian Medical Journal (2003) $251-258$, at 253 .

${ }^{27}$ The accused has the right to a trial 'without undue delay' (Art. 21(4) ICTYSt).

${ }^{28}$ N.M. Browne, T.J. Keeley, and W.J. Hiers, 'The Epistemological Role of Expert Witnesses and Toxic Torts', 36 American Business Law Journal (1998) 1-72, at 39.

${ }^{29}$ Stover and Shigekane report that during the Kosovo investigations the agenda was to investigate as much and as quickly as possible (E. Stover and R. Shigekane, 'Exhumation of Mass Graves: Balancing Legal and Humanitarian Needs', in E. Stover and H.M. Weinstein (eds), My Neighbor, My Enemy: Justice and Community in the Aftermath of Mass Atrocity (Cambridge: Cambridge University Press, 2004) 85-103).
} 
- to determine the gender [sic] of the victims;

- to identify any links between primary mass graves and secondary mass grave sites;

- to identify links to the perpetrators. ${ }^{30}$

The on site briefings by the investigator should contain factual and background information 'avoiding speculative scenarios which could bias the expert to try to prove the prosecutor's theory of a case. ${ }^{31}$ Amongst forensic experts this triggers the debate about how many or how few facts to provide and views may differ between individuals and the various forensic disciplines. ${ }^{32}$ If it is assumed that facts are neutral pieces of information, value-free data, then can facts ever stop being neutrally informative and start corrupting an investigation? Even if science is free of irrational prejudice, can the experts remain prejudice-free when given a brief or when the investigators seek subtly to influence the investigation? A scientist's everyday life is about establishing and disproving hypotheses. Providing a forensic expert with a prosecution theory, so defence lawyers argue, will guide forensic activities in a certain direction, thus, influencing the investigation to the detriment of the neutral and objective overall view. When asked during cross-examination whether forensic pathologists are expected to prove the theory of the prosecution, pathologist Dr Christopher Lawrence replied:

\footnotetext{
${ }^{30}$ Milošević Witness Statement by Investigations Team Leader Dean Paul Manning, supra note 16, § 9.

${ }^{31}$ Skinner and Sterenberg, supra note 17, at 223.

${ }^{32}$ Recently during the Popovic et al. trial the defender asked Chief Pathologist Dr John Clark during crossexamination about the briefing received by ICTY investigators before the Srebrenica autopsies. Dr Clark replied that they had received 'remarkably little information' which, in his view, was positive. He went on to explain his point: 'There is an argument whether we should ... do a case sort of blind or with some information. I think there is a happy medium. I think we probably reached this here, and certainly we had little detailed information about the cases. Other than to the extent that we were generally informed whether this was a primary grave of whether this was a grave which had been disturbed, and that explained why so many of the bodies were disrupted. ... but in terms of what weapons had been used, ... we were the main instigators of that information from our findings.' (Trial Transcript, Popović et al. (IT-05-88-T), Trial Chamber, 19 February 2007, $7348-7349$ (hereinafter Popović et al. Trial Transcript)).
} 
No. My job as a forensic pathologist in this, along with everything else I do, is to test the information that I have been given to see if it is true. In the course of any investigation that I do, I am given information but it is my job to test that information to see if it is correct. ${ }^{33}$

Testing, in the context of atrocity crime investigations, means to examine the body for clothing, personal possessions, identifying features, taphonomic characteristics, blindfolds, ligatures, gunshot injuries, blast injuries, sharp and blunt-force trauma, burning, dismemberment etc. ${ }^{34}$ Similarly, archaeologists and anthropologists at the site employ methods, such as surveying, trenching and excavating, to gather information before analysing it.

Forensic science faces a paradox with regard to the best level of briefing: whilst more background information implies a greater involvement with the prosecution's strategies, it can underpin the quality of research by raising the experts' awareness of details and potential evidence. ${ }^{35}$ Some argue that it is simplistic to believe that forensic experts remain impartial when given little information:

First, there may be no simple or uncontroversial way of separating 'scientific' facts from their 'background' context. And secondly, the umbrella term 'forensic science' embraces a set of intensely practical disciplines to which the paradigm of pure scientific enquiry cannot readily be applied. ${ }^{36}$

Indeed, it must be noted that forensic work at exhumation or mortuary sites is not a 'pure' science in the sense that hypotheses can be experimentally tested.

\footnotetext{
${ }^{33}$ Ibid., 21 February 2007, 7519.

${ }_{35}^{34}$ Clark, supra note 25 , at 368 .

${ }^{35}$ The Role of Forensic Science Evidence in Criminal Proceedings report suggests a solution to the dilemma: 'Insofar as the provision of extra background information may pose a threat to the independence of the forensic scientist, this may need to be offset by strengthened procedures to ensure that their work is scrutinized by qualified and experienced defence experts' (The Royal Commission on Criminal Justice, 'The Role of Forensic Science Evidence in Criminal Proceedings', Research Study 11 (London: HMSO, 1993), 36).

${ }^{36}$ Ibid., at 30 .
} 


\section{Science and Forensic Science}

Science is a 'valued means of getting to know the world. ${ }^{37}$ Scientific activity directed to this goal is based on the scientific ethos of 'universalism, organized scepticism, communality, ethical neutrality, and disinterestedness ${ }^{38}$ and adherence to the code should make science value-free. However, science and the way in which the scientific community operates cannot exclude arbitrary elements in their quest for knowledge. ${ }^{39}$ Furthermore, science cannot claim that its pronouncements are certain, they are merely the most probable given the present evidence, and the practice of science cannot be separated from the social sphere. The view that 'scientists are not disintegrated agents but rather are immersed in a web of relations that play an important role in determining the character of truths that emerge from their interaction ${ }^{40}$ gained considerable ground. With experts trying to conform to and operate within scientifically accepted, but socially constructed, knowledge, the outcome of scientific analysis is predestined to fit this particular set of thoughts.

That science does not operate outside the social dimension is particularly true of forensic science, whose root in the Latin word forensis (meaning publicly, belonging to the market, to the court ${ }^{41}$ ) implies the legal and social aspects. Forensic science is embedded in the social process of legal inquiry and the social sphere is the reason for its

\footnotetext{
${ }^{37}$ B. Russell, The Impact of Science on Society (London: Unwin Books, 1968), 73.

${ }^{38}$ R.A. Rothman, 'A Dissenting View on the Scientific Ethos', 23 The British Journal of Sociology (1972) 102-108, at 102. Rothman expands on the four norms of science (universalism, communism, disinterestedness, and organised scepticism) proposed by Robert K. Merton.

${ }^{39}$ Browne et al., supra note 28, at 50.

${ }^{40} \mathrm{Ibid}$. Lorin de la Grandmaison and his colleagues claim that most pathologists involved in the ICTY investigations came from NATO member states. It was NATO, however, who dropped bombs against the Serbian army in Kosovo in 1999. The article suggests that the country of origin, its foreign policy and media reports may have an effect on those involved in investigation, thus introducing conscious or unconscious bias (de La Grandmaison et al., supra note 23).

${ }^{41}$ R. Hau and E. Kulf, Pons Globalwörterbuch Lateinisch-Deutsch (Köln: Klett, 1991).
} 
existence: to reconstruct events that happened in the past. This is not to reject the scientific knowledge or truth it produces per se. It does, however, raise the question of how this knowledge is produced to then be interpreted in court.

The term 'forensic science' is problematic for an understanding of what it produces and what methods are adopted throughout the process of forensic investigations. Forensic science suggests a unity which does not exist: Under the homogenous term lie many heterogeneous disciplines (archaeology, anthropology, pathology, radiography, molecular biology etc.) with the potential to produce different pieces of information. In fact, the disciplines with which this paper is concerned, strictly speaking, do not qualify as 'pure' science but rather as 'applied science' or 'medical science'. ${ }^{42}$ Archaeology and anthropology, for example, are concerned with recording and collecting human and material remains. They follow protocols and employ distinct methods for both the datagathering and data-analysis phases. ${ }^{43}$ These methods are designed to help the experts make decisions regarding their findings, but the methods themselves can operate with ordinal categories, as opposed to defined measurable intervals, making the process subjective and qualitative in nature. 'One of the most common problems faced by forensic anthropologists', writes Byers in his forensic anthropology textbook, 'is how to make a single determination from ambiguous data. ${ }^{44}$ Although techniques employed during anthropological and archaeological investigations must be consistent with 'established scientific principles, validated and, preferably, published so they can be

\footnotetext{
${ }^{42}$ S. Byers, Introduction to Forensic Anthropology, (3rd edn, Boston: Pearson, 2008), 1.

${ }^{43}$ Anthropologists use anthroposcopic, osteometric, chemical and histologic methods for data generations and range charts, indexes, discriminant functions and regression equations for concise analysis (Ibid., at 16).

${ }^{44}$ Ibid.
} 
scrutinized by the scientific community at large,${ }^{45}$ the decisions made are more often concerned with probabilities rather than certainties. Consequently, forensic evidence is formed though both scientific and non-scientific factors. Given that many of the findings are subject to dispute, protocols ensuring consistency and reliability in the order and application of techniques become paramount. Forensic science, especially in the context of exhumation and autopsy, relies on adherence to procedures and professional experience as a quality control, because the evidence can only be collected once - there is no room for experiments. This is why recording each step during the process is so important before the material is analysed.

\section{Report}

Findings from the exhumation site and mortuary are summarised in individual reports prepared by the chief anthropologist, chief archaeologist and chief pathologist and by those responsible for other site-unrelated scientific investigations. ${ }^{46}$ They contain information on the minimum number of individuals located in the exhumed graves, sex of the deceased, cause of death as well as presence of blindfolds and ligatures. ${ }^{47}$ The scientists weigh the data and decide whether to include limitations of analysis or exclude certain facts from their reports - they are selective. In this sense, the report, as the process of documenting and interpreting the evidence, is an act of selected knowledge creation

\footnotetext{
${ }^{45}$ Cobb, supra note 11 , at 9.

${ }^{46}$ For the Srebrenica investigations, six additional scientific examinations of recovered material were conducted, analysing mineralogical and pollen samples, self-winding watches (located in the mass graves) blood and tissue samples, suspected explosive residue, shell cases as well as cloth blindfolds and ligatures (see Manning, supra note 7, at 12-15).

${ }^{47}$ Ibid.
} 
and contains, for the purpose of this article, 'forensic truth'. 'Forensic truth' can thus be defined as the constructed theory of what is likely to be true given the circumstances.

The report makes this 'forensic truth' accessible to others and needs to be intelligible, clear and unambiguous whilst explaining all the important scientific findings. ${ }^{48}$ These reports are reviewed by the investigator and forwarded to The Hague. ${ }^{49}$ Whilst the investigator empowers and limits the forensic scientists in their pursuit of evidence, the report, created for a cause beyond the forensic scientists' control, empowers and limits the prosecution's claims in court. Forensic science, despite its limits, aspires to objective and independent truth, whereas in the legal arena it is used by the parties to persuade the judges to believe a particular version of the truth.

\section{4. 'Forensic Truth' in Court}

Legal systems, in their administration of justice, rely on the assistance of scientists ${ }^{50}$ and the ICTY is no exception. Experts are consulted to aid in the process of establishing a factual account of events. However, forensic evidence is admitted not because of its truthfulness per se, but because it is relevant to a case. Hence it is important to realise 'that science enters the courtroom not in the form of bare facts or claimed truths about the world, but as evidence. ${ }^{51}$ Rule 95 of the ICTY Rules of Procedure and Evidence ${ }^{52}$ regulates the admissibility of evidence:

\footnotetext{
${ }^{48}$ Skinner et al. provide a description of what a report should contain (Skinner et al., supra note 24, at 9192).

${ }^{49}$ Although reports may be tendered as evidence in a case, the authors of the reports are not necessarily asked to become expert witnesses during the trial.

${ }^{50}$ M. Freeman, 'Law and Science: Science and Law', in M. Freeman and H. Reece (eds), Science in Court (Aldershot: Ashgate, 1998) 1-9.

${ }^{51}$ Jasanoff, supra note 4, at 329.
} 
No evidence shall be admissible if obtained by methods which cast substantial doubt on its reliability or if its admission is antithetical to, and would seriously damage, the integrity of the proceeding. ${ }^{53}$

With no mention of the scientific standards to be adhered to, this exclusionary rule is in stark contrast to the Daubert Guidelines which determine whether expert evidence is scientific and therefore admissible under Federal Rule $702^{54}$ in US courts, as summarised by Christensen:

1. The content of the testimony can be (and has been) tested using the scientific method.

2. The technique has been subject to peer review, preferably in the form of publication in peer reviewed literature.

3. There are consistently and reliably applied professional standards and known or potential error rates for the technique.

4. Consider general acceptance within the relevant scientific community. ${ }^{55}$

Nevertheless, during examination and cross-examination some of the criteria outlined by the Daubert Guidelines were tested during the Krstić trial.

\section{A. 'Forensic Truth' as Part of the Legal Narrative}

'Despite the maze of legal jargon, lawyers' mysterious tactics, and obscure court procedures, any criminal case can be reduced to the simple form of a story. ${ }^{56}$ During the Kristić trial, forensic evidence became part of a narrative with over 12 days dedicated to examining forensic exhibits and hearing expert witnesses regarding the examination of

\footnotetext{
${ }^{52}$ The Rules of Procedure and Evidence were drafted by the ICTY judges and have been amended according to the experiences gained by the Tribunal throughout its existence (May and Wierda, supra note 3 ). One of the primary purposes of the rules of procedures is to protect 'the rights of the accused for the duration of the entire proceedings, pre-trial to sentencing .... Con-sequently, all of the rules can be understood at some level in terms of the accused's rights' (Rutledge supra note 3, at 181).

${ }^{53}$ Rule 21(4) ICTY RPE.

${ }^{54}$ For an explanation of the Daubert guidelines and its predecessor, the Frye test, see Byers, supra note 42; Browne et al., supra note 4; Browne et al., supra note 28 and A.M. Christensen, 'The Impact of Daubert: Implications for Testimony', 49, no.3 Journal of Forensic Science (2004) 1-4.

${ }_{55}^{55} \mathrm{Ibid}$., at 2.

56 W.L. Bennett and M.S. Feldman, Reconstructing Reality in the Courtroom (London: Tavistock Publications, 1981), 4.
} 
execution points, primary and secondary graves. Eight expert witnesses were called by the Prosecution to give evidence about the forensic findings. ${ }^{57}$ Expert witnesses are first examined by the prosecution, then by the defence and lastly by the judges. The examination of expert witnesses is based on the report they wrote and complemented by forensic exhibits.

During the trial, the expert witness is a "servant to the court. ${ }^{58}$ After the solemn declaration, the witness 'is a witness of truth before the Tribunal and, inasmuch as he or she is required to contribute to the establishment of truth, not strictly a witness for either party. ${ }^{59}$ The role of an expert witness is to provide impartial and neutral evidence to enhance the tribunal's understanding of events. Whilst Cobb insists that ' $[\mathrm{t}] \mathrm{he}$ scientist can only give evidence on work carried out personally or under direct supervision', he can comment on and interpret factual evidence given by another witness under oath in the light of scientific findings and knowledge. ${ }^{60} \mathrm{He}$ specifically emphasises that the forensic scientist is personally responsible for his or her results and analysis, not corporately accountable. Nevertheless, at the ICTY experts testified on behalf of their forensic team because of the vast number of forensic experts employed during the process and the rotational aspect of deployment. ${ }^{61}$

\footnotetext{
${ }^{57}$ Two experts were forensic anthropologists (Jose-Pablo Baraybar and Dr William Haglund), two forensic pathologists (Dr John Clark and Dr Christopher Lawrence), one forensic archaeologist (Prof. Richard Wright), one demographer (Dr Helge Brunborg) and two ICTY investigators (Dean Manning and JeanRene Ruez).

${ }^{58}$ T. Rothwell, 'Presentation of Expert Forensic Evidence', in P. White (ed), Crime Scene to Court: The Essentials of Forensic Science (Cambridge: The Royal Society of Chemistry, 1998) 327-351, at 349.

${ }^{59}$ Decision on Communication between the Parties and their Witnesses, Kupreškić et al. (IT-95-16-T), Trial Chamber, 21 September 1998.

${ }^{60} \mathrm{Cobb}$, supra note 11, at 9.

${ }^{61}$ Many team members could only be present for a few weeks at a time depending on their employers' capacity to release them. This was particularly the case for professionals such as police officers, pathologists, odontologists and radiographers (Margaret Cox, Personal Communication, 5 July 2007).
} 
How does the prosecution create a plausible narrative through the use of forensic evidence? Although forensic evidence in its construction may be limited, 'when executed correctly, the results are viewed as no longer bearing traces of human subjectivity. ${ }^{62}$ For this reason, the prosecution aims to present the expert and the findings as being as convincing and reliable as possible. At the ICTY, there are, however, no clear-cut criteria to determine the expert status of a witness. ${ }^{63}$ In Krstić, therefore, prosecution lawyer Peter McCloskey asked archaeologist and expert witness Professor Richard Wright to outline his educational and professional background, his experience and that of his team members in order to establish the expert as a credible source of information before questioning him about his methods, findings and interpretations. ${ }^{64}$ Although it was not mentioned explicitly during the Krstić trial, emphasising adherence to protocols can help argue for a small error margin and create the image of 'proper' science. During the exhumations protocols were in place, however, because conditions at a site differ from grave to grave, they were relatively flexible to allow experts to adapt to each situation. The protocols used under Professor Wright comprised a two page document with procedures regarding individual team member responsibilities, surveying of the site and its surroundings, assignment of numbers to artefacts, bodies and body parts, keeping logs, photographing in situ, transfer of the items of evidence from the site, packaging and storage, and logs as to who attended the site. ${ }^{65}$ The procedures were complemented by a

\footnotetext{
${ }^{62}$ Jasanoff, supra note 4, at 330.

${ }^{63}$ Rutledge, supra note 3, at 177.

${ }^{64}$ Trial Transcript, Krstić (IT-98-33-T), Trial Chamber, 28 May 2000, 3633-3642 (hereinafter Krstić Trial Transcript).

${ }^{65}$ R. Wright, 'General Procedures for ICTY Exhumations at *****[site name].' (unpublished document, 2000). Having an inflexible protocol can indeed be disadvantageous for the prosecution as deviation from the protocol may demand justification and damage witness and evidence credibility. However, this can be offset by processes regulating deviations from the norm, explaining why changes have been made, but in turn that introduces more paperwork and might be impractical.
} 
Checklist for Location, Attitudes and Properties of a Skeletonised Body, where the forensic archaeologist or anthropologist could indicate the properties of the bodies found. ${ }^{66}$

The forensic evidence tendered by the prosecution regarding the Srebrenica investigations revealed that between 1996 and the end of 1999, the minimum number of individuals located in the exhumed graves was 1883. A further 2571 individuals at least were believed to be buried in examined but un-exhumed sites. Of the individuals recovered, 1656 were positively determined to be male, one was female, whilst the sex of 220 remained undetermined. During exhumation and autopsy, 270 blindfolds and 407 ligatures were found. Autopsies confirmed that hundreds had died of gunshot wounds. For each of the exhumation sites, the sex, age and cause of death of the individuals recovered was listed, as well as ligatures, blindfolds, shell cases, bullets, identification artefacts and religious artefacts. ${ }^{67}$

\section{B. Legal Deconstruction}

Given that forensic evidence is constructed, Jasanoff claims that what is presented as fact or truth needs to be 'legally deconstructed' ${ }^{68}$ There is no better tool than crossexamination to unravel knowledge claims. Cross-examination, an adversarial element within the ICTY structure, aims 'to elicit information favourable to the party on whose

\footnotetext{
${ }^{66}$ R. Wright, 'Checklist for Location, Attitudes and Properties of a Skeletonised Body. (unpublished document, 2000).

${ }^{67}$ Manning, supra note 7.

${ }^{68}$ S. Jasanoff, 'What Judges Should Know About the Sociology of Science', 32 (Spring) Jurimetrics (1992) 345-359, at 348 .
} 
behalf it is conducted and to cast doubt on the accuracy of evidence given against that party $^{69}$ or indeed to discredit the witness.

Law and science literature refers to the term 'boundary-work' - an attempt to create a strong image of science by contrasting it favourably to other, non-scientific intellectual activities ${ }^{70}$ - as one means of shielding scientific work from challenges. During a trial, prosecution and defence parties operate with the boundary-work notions of expansion, monopolisation, protection and expulsion to establish expert credibility or indeed to discredit opposing experts. ${ }^{71}$ The parties aim to suggest that their expert's authority and expertise extends into other domains and professions (expansion), or that the expertise of their witness is the most appropriate to be called in relation to the case at hand (monopolisation) or to protect them from outside criticism (protection), or indeed to exclude those who do not belong to the profession, labelling them as 'non-members' (expulsion). All this is done in an attempt to either affirm or discredit the credibility of a witness, the credibility of findings or the credibility of methods and protocols to make a narrative more plausible.

The cross-examination during the Krstic trial sought to establish that some of the deceased had died in combat. The anthropologist could not deny that possibility, ${ }^{72}$ nor could the pathologist disagree with the defence that some injuries may have happened post-mortem. ${ }^{73}$ However, the defence's cross-examination hardly attempted to discredit

\footnotetext{
${ }^{69}$ E.A. Martin and J. Law (eds), Oxford Dictionary of Law (6th edn, Oxford: Oxford University Press, 2006), 142.

${ }^{70}$ T.F. Gieryn, 'Boundary-Work and the Demarcation of Science from Non-Science: Strains and Interests in Professional Ideologies of Scientists', 48, no.6 American Sociological Review (1983) 781-795.

${ }^{71}$ Edmond, supra note 4, at 384.

72 See Anthropologist Jose Pablo Baraybar's testimony (Krstić Trial Transcript, supra note 64, 30 May 2000, 3859).

${ }^{73}$ See Dr Clark's cross-examination (Ibid., 31 May 2000, 3957).
} 
the forensic evidence provided. ${ }^{74}$ Even defence expert Dr Zoran Stankovic, although challenging some of the forensic investigations into cause of death, claiming that some had been killed in combat, 'accepted that the exhumations were conducted by experts with "substantial professional experience and adequate technical, scientific and moral integrity". ${ }^{75}$

\section{C. 'Procedural Truth'}

The ICTY adopts a mixture of adversarial and inquisitorial elements to administer justice. Whilst the adversarial model relies on 'zealous advocacy', it still strives to 'seek a "truth"; one that is fair and just; not necessarily an objective or descriptive truth. ${ }^{76}$ The inquisitorial approach, on the other hand, aims for an

... approximation to the historical facts, and the process is geared toward finding these facts to the extent necessary for a credible judgment, regardless of the wishes of individual participants. ${ }^{77}$

The rationale for a mixed system is the belief that the closest grasp of the truth can be achieved through a neutral investigation with adversarial presentational elements - hence the cross-examination of witnesses. Judges are likely to hear more than one expert and are subjected to the experts' multiple perspectives in order to establish some form of truth on which to base justice. Indeed, this poses an epistemological problem: how to establish what is legitimate or illegitimate knowledge? In order to answer this question, judges

\footnotetext{
${ }^{74}$ This is not the case for the Popovic et al. trial, where forensic scientist had to defend their standards and methods more vigorously. See for example cross-examination of anthropologist Dr William Haglund (Popović et al. Trial Transcript, supra note 3215 March 2007, 8930-9008).

${ }^{75}$ Judgment, Krstić (IT-98-33-T), Trial Chamber, 2 August 2001, § 76 (hereinafter Krstić Judgment).

${ }^{76}$ Browne et al., supra note 28, at 39.

${ }^{77}$ Weigend, supra note 5, at 171.
} 
need to have an idea as to how the 'forensic truth' has been created before deciding how to weigh its relevance and credibility.

Given the difficulty of establishing what is and what is not 'forensic truth', Browne argues for a

... dynamic conception of epistemology that retains the idea that there can be epistemic legitimacy while at the same time emphasizing its contested nature and the process whereby conflicts concerning it emerge and are settled through exclusion, appropriation, or some other means. ${ }^{78}$

Applying the criteria of consistency, appropriation and convincingness, whilst being aware of the social and traditional influences on judgments, is what the judges are left with. In the criminal justice context, legal scholars like Weigend thus prefer to speak of legal truth or "procedural truth, a function of what the process is to achieve'. ${ }^{79}$ 'Procedural truth', in the words of Naqvi, would suggest 'agreement about factual reality but also space for differing interpretations. ${ }^{80}$

What did the judges make of the 'forensic truth' presented to them during the Krstic trial? The fact that it was admitted does not indicate how much weight was attributed to its claims. Did the judges accept it as facts to base their verdict on? They first had to establish whether the crime of genocide had been committed before deciding whether Radislav Krstić was guilty of it. The Trial Chamber found that the forensic evidence corroborated important aspects of the testimony of survivors from the execution sites ${ }^{81}$ and was sufficiently credible and compelling to confirm the actus reus of genocide. The judges concluded that 'following the take-over of Srebrenica, thousands

\footnotetext{
${ }^{78}$ Browne et al., supra note 28, at 51.

${ }^{79}$ Weigend, supra note 5, at 170.

${ }^{80}$ Y. Naqvi, 'The Right to the Truth in International Law: Fact or Fiction?', 88 International Review of the Red Cross (2006) 245-273, at 272.

${ }^{81}$ Krstić Judgment, supra note $75, \S 71$.
} 
of Bosnian Muslims were summarily executed and consigned to mass graves' ${ }^{82}$ Furthermore, the Trial Chamber found that forensic evidence suggesting that the majority of bodies exhumed had not been killed in combat was conclusive and decided that most of the over 7,000 missing people had been executed and buried in mass graves. ${ }^{83}$ The disappearance of generations of men, reasoned the Trial Chamber, showed the intent to physically destroy Bosnian Muslims. Forensic evidence provided further indication of the intent to destroy the group, as such, due to the findings that executions had followed a 'well-established pattern' ${ }^{, 84}$ and that bodies were not only concealed in mass graves, but were later dug up in an attempt to hide the crimes. The seven exhumed secondary graves contained commingled and mutilated body parts rendering identification as well as appropriate burials extremely difficult, thus causing further distress to the survivors.

The Trial Chamber, once satisfied that genocide had occurred, then examined whether Krstic had shared the intention to carry out genocide. The fact that all located and examined gravesites associated with the Srebrenica incident were within the Drina Corps area of responsibility contributed to the Trial Chamber's overall notion that Krstic was aware of the genocide: 'due to their massive nature and the level of co-operation required, the executions [and the re-burials] could not have been accomplished in isolation from the Drina Corps Command. ${ }^{85}$ Furthermore, despite the absence of forensic evidence to suggest that General Krstić had been present at any of the executions, the Trial Chamber was satisfied that he had participated in the joint criminal

\footnotetext{
${ }^{82}$ Ibid., § 73.

${ }^{83} \mathrm{Ibid}$., § 82.

${ }^{84}$ Ibid., § 68.

${ }^{85}$ Ibid., § 276.
} 
enterprise and shared the genocidal intent to kill the Bosnian Muslims. Consequently, on $2^{\text {nd }}$ August 2001, Radislav Krstić was found guilty of genocide.

On appeal, however, this verdict was overturned. The Appeals Chamber concurred with the Trial Chamber that the Bosnian Muslims of Srebrenica did qualify as a protected group under Article 4 of the ICTY Statute. Furthermore, the Appeals Chamber agreed with the Trial Chamber that 'some members of the VRS Main staff intended to destroy Bosnian Muslims, ${ }^{86}$ targeting for extinction the 40,000 Bosnian Muslims living in Srebrenica. But according to the Appeals Chamber, the cardinal question as to whether Krstić had had the necessary intent to commit genocide was not proven; it criticised the Trial Chamber for its 'failure to supply adequate proof that Radislav Krstić possessed genocidal intent,' ruling that Krstić 'is not guilty of genocide as a principal perpetrator. ${ }^{87}$ Instead the Appeals Chamber limited his liability in the joint criminal enterprise and

... found Radislav Krstić responsible as an aider and abettor to genocide and to murders as a violation of the law or customs of war committed between 13 and 19 July 1995, instead of as a co-perpetrator, as found by the Trial Chamber. ${ }^{88}$

In order to give judgment, the judges had to rule on the base crime, the context, before contemplating the guilt of the accused. In this sense, 'forensic truth' had a part to play, convincing them of the factuality of the forensic accounts. Forensic evidence from the mass graves helped to define the targeted group as Bosnian Muslims; it contributed to the ruling that the intent to commit genocide existed, through demonstrating the

\footnotetext{
${ }^{86}$ Judgement, Krstić (IT-98-33-A), Appeals Chamber, 19 April 2004, § 26.

${ }^{87}$ Ibid., $\$ 134$.

${ }^{88}$ Ibid., $\$ 266$.
} 
systematic nature of the killings; it showed that many of the dead were civilians and that attempts had been made to conceal the crimes. Furthermore, through the location and excavation of the mass graves, forensic science assisted in outlining the amount of cooperation required to undertake such executions and burials, thus indirectly suggesting the involvement or knowledge of the Drina Corps which ultimately led to implicating its commander, General Krstić. However, forensic evidence did not establish a direct link between Krstić and the killings.

The Krstic ruling and its use of forensic evidence has since been relevant to other Srebrenica cases, especially Blagojević, Popović et al, and the Milošević case, as he was charged inter alia with genocide and complicity in genocide in Bosnia and Herzegovina. Similarly, in the 2007 Genocide case, the International Court of Justice (ICJ) referred repeatedly to the Krstic judgments (both of the Trial and the Appeals Chamber), particularly regarding the definition of the protected group within a geographically limited area ${ }^{89}$ and the massacres at Srebrenica. ${ }^{90}$ Without specifically mentioning forensic science exhumations, the ICJ referred to the Krstic case and its conclusion that 'the actus reus of killings in Article II $(a)$ of the Convention was satisfied'. ${ }^{91}$ In relation to intent, the ICJ quoted the Trial Chamber's findings that many non-combatant Bosnian Muslim men of military age had been targeted, the executions had happened on a large scale and the killing methods had been invariable, thus referring to evidence generated through forensic science and presented during Krstic. ${ }^{92}$

\footnotetext{
${ }^{89}$ See Case Concerning the Application of the Convention on the Prevention and Punishment of the Crime of Genocide (Bosnia and Herzegovina v. Serbia and Montenegro), International Court of Justice, 26 February 2007, § 197.

${ }^{90}$ Ibid., $\S \S 278,281,290$ and 292.

${ }^{91}$ Ibid., $§ 290$.

${ }^{92}$ Ibid., § 292.
} 
With the Krstić ruling that genocide had indeed taken place, and in accepting forensic evidence as truthful, a judicial record was created that has since had ramifications for other trials and been accepted by many as an account of reality. International law expert Martti Koskienniemi notes that in war crimes trials, such as Krstić, the emphasis is on judging the individual and interpreting the historical and political context. International criminal trials are thus seen 'to be conducting a political trial to the extent that what those facts are, and how they should be understood, is part of the conflict that is being adjudged. ${ }^{93}$ Such politically connotative 'procedural truth', as indeed any form of truth according to post-modern thinker Foucault, has its limitations:

Truth is produced only by virtue of multiple forms of constraint. And it induces regular effects of power. Each society has its régime of truth, its 'general politics' of truth: that is, the types of discourse which it accepts and makes function as true; the mechanisms and instances which enable one to distinguish true and false statements, the means by which each is sanctioned; the techniques and procedures accorded value in the acquisition of truth; the status of those who are charged with saying what counts as true. ${ }^{94}$

Simply because trials aim to produce an impartial, authoritative account about past events does not mean they will be successful in this quest, nor does it mean that this new record will not be distorted for various political or personal reasons. A study into the perception of justice, accountability and social reconstruction amongst Bosnian judges and prosecutors, suggested that 'a historical record with a legal imprint ${ }^{95}$ in the manner of the ICTY is not always acceptable to them. The study's finding states that

\footnotetext{
${ }^{93}$ M. Koskenniemi, 'Between Impunity and Show Trials', in J.A. Frowein and R. Wolfrum (eds), Max Planck Yearbook of United Nations Law (Leiden: Martinus Njihoof Publishers, 2002) 1-36, at 33.

${ }^{94}$ M. Foucault, Power/Knowledge - Selected Interviews and Other Writings 1972-1977, ed. Colin Gordon (New York: Prentice Hall, 1980), 131.

${ }_{95}$ Naqvi, supra note 80 , at 246.
} 
[a]though international trials render verdicts based on an examination of "facts," the responses of our participants indicate that their perception of truth may outweigh the facts as determined by an international body. ${ }^{96}$

Evidence generated through forensic science increases the independence and impartiality of these facts: Although the judicial interpretation of facts can be highly disputed, the information from forensic examinations speaks, to some degree, for itself. Despite the constructed nature of 'forensic truth', it is invaluable to international criminal justice because it produces a truth of its own. Whilst some may query whether genocide happened, ${ }^{97}$ forensic exhumations and the physical evidence they produced from the graves make it very difficult to deny that hundreds of Bosnian Muslim men were executed.

\section{Conclusion}

Shedding light on the premises and parameters within which forensic experts operate is not intended to criticize their profession and scientific procedures. Science as a means of discovery is a very powerful (if not the most powerful) tool human kind has to explore and reveal truths about the world we live in. ${ }^{98}$ Nor does this article aim to solve the epistemological difficulties about how to adjudicate, but rather to give an overview of the main issues involved during the 'forensic expertise meets international law' interface;

\footnotetext{
${ }^{96}$ The Human Rights Center and the International Human Rights Law Clinic, University of California, Berkeley, and the Centre for Human Rights, University of Sarajevo, 'Justice, Accountability and Social Reconstruction: An Interview Study of Bosnian Judges and Prosecutors', 18 Berkeley Journal of International Law (2000) 102-164, at 151.

${ }^{97}$ When questioned whether genocide had happened anywhere in Bosnia and Herzegovina, all Bosniak legal professionals agreed that genocide against Bosniaks had occurred, while Bosnian Serb respondents' answer were more mixed: some acknowledged that genocide had happened against all sides, others said they had no knowledge of crimes qualifying as genocide or that genocide had not happened. Bosnian Croat legal professionals, again, acknowledged that genocide had happened but that all three sides had been subjected to it (Ibid. 147-148).

${ }^{98}$ P. Atkins, 'Science as Truth', 8 History of the Human Sciences (1995) 97-102.
} 
this in turn will help develop a theoretical framework to optimise activities, and minimise deficiencies, of forensic investigations.

During atrocity crime investigations, forensic expertise successfully provides evidence within a legal context and its own socially constructed reality. It is from the outset inherently limited in its construction through its link with the prosecution and its limits as an applied science, yet it yields vital expert information for use in court where it is employed to bolster legal narratives. Indeed, the article outlines means to counterbalance the limitations through the adoption of professional standards and operating procedures, the use of established scientific techniques and rigorous peer review. The resulting 'forensic truth' has to withstand cross-examination before judges decide on its credibility and reliability. To help prove that genocide actually occurred - whether intended or facilitated by Krstić - forensic evidence and other corroborating material were sufficient to convince both the Trial and the Appeals Chamber. Further to the conceptual exploration of the issues described here, it remains to be analysed how ethical and professional standards affect the creation of forensic evidence during the investigation and in court and what would happen if forensic science and legal operations produced incompatible accounts of the same event. ${ }^{99}$

In light of the constructed nature of 'forensic truth', no matter how hard the experts strive for objectivity and independence, it becomes difficult to keep the positivistic ideal of searching for 'the truth' alive. Legal scholars and forensic experts alike may indeed favour the constructivist perspective of truth as a social construct. ${ }^{100}$ Replacing the quest for 'the truth' with the more modest aim to establish 'a truth', may be

\footnotetext{
${ }^{99}$ See D. Nelken, 'A Just Measure of Science', in M. Freeman and H. Reece (eds) Science in Court, Issues in Law and Society (Aldershot: Ashgate, 1998) 11-36, at 13.

${ }^{100}$ Browne et al. supra note 4 , at 73 .
} 
more appropriate, especially since all legal systems, including the ICTY, are also socially constructed and rely on political will, despite some legal scholars and human rights activists arguing that justice is universal and above politics:

... such positivist notions fail to recognize that courts, like all institutions, exist because of, not in spite of politics. People and entire communities can interpret a tribunal's decisions, procedures (modes and manner of investigations, selection of cases, timing of trials, types and severity of punishments), and even its very existence in a variety of ways. Indeed, politics in this sense is imbedded in everything, especially the pursuit of justice. ${ }^{101}$

International criminal tribunals contribute to satisfying a plethora of needs of populations emerging from conflict. Through its use of forensic evidence and the verdicts it pronounces, the ICTY contributes to establishing $a$ record of the past, acknowledging the victims and preventing impunity, historical revisionism and denial. To expect more from 'forensic truth' and the tribunal's 'procedural truth' would be 'wishful thinking'. ${ }^{102}$

${ }^{101}$ F. Abrahams, G. Peress, and E. Stover, A Village Destroyed, May 14, 1999 (Berkeley: University of California Press, 2001), 94.

${ }^{102} \mathrm{Ibid}$., at 95. 